\title{
Effect of Er,Cr:YSGG laser surface conditioning on the adhesion of fiber- reinforced composite and zirconia intraradicular posts to the root dentin
}

Cengiz, Seda ; Koçak, Sibel ; Koçak, Murat ; Velioğlu, Neslin ; Sadettinoğlu, Koray ; Òzcan, Mutlu

DOI: https://doi.org/10.1080/01694243.2016.1170587

Posted at the Zurich Open Repository and Archive, University of Zurich ZORA URL: https://doi.org/10.5167/uzh-128164

Journal Article

Accepted Version

Originally published at:

Cengiz, Seda; Koçak, Sibel; Koçak, Murat; Velioğlu, Neslin; Sadettinoğlu, Koray; Òzcan, Mutlu (2016). Effect of Er,Cr:YSGG laser surface conditioning on the adhesion of fiber- reinforced composite and zirconia intraradicular posts to the root dentin. Journal of Adhesion Science and Technology, 30(18):1957-1967.

DOI: https://doi.org/10.1080/01694243.2016.1170587 
Effect of Er,Cr:YSGG laser surface conditioning on the adhesion of fiber reinforced composite and zirconia intraradicular posts to the root dentin

\author{
Seda Cengiz, DDS, $\mathrm{PhD}^{\mathrm{a}^{*}} /$ Sibel Koçak, DDS, $\mathrm{PhD}^{\mathrm{b}} /$ Murat Koçak, DDS, $\mathrm{PhD}^{\mathrm{b}} /$ Neslin \\ Velioğlu DDS, PhD ${ }^{\mathrm{a}}$ / Koray Sadettinoğlu, DDS ${ }^{\mathrm{c}} /$ Mutlu Özcan, DDS, Dr.med.dent., \\ $\mathrm{PhD}^{\mathrm{d}}$
}

${ }^{a}$ Assistant Professor, Bülent Ecevit University, Faculty of Dentistry, Department of Prosthodontics, Zonguldak, Turkey

${ }^{b}$ Associate Professor, Bülent Ecevit University, Faculty of Dentistry, Department of Endodontics, Zonguldak, Turkey

${ }^{c}$ Specialist Dentist, İstanbul Oral and Dental Health Clinic, Istanbul, Turkey

${ }^{d}$ Professor, Univesity of Zurich, Dental Materials Unit, Center for Dental and Oral Medicine, Clinic for Fixed and Removable Prosthodontics and Dental Materials Science, Zurich, Switzerland

Short title: Effect of laser conditioning on root posts to dentin

Part of this study has been presented as oral presentation at the 12th International Congress of Turkish Endodontics Society, May, 15-17th, 2014, Istanbul, Turkey.

Correspondance to: Dr. Seda Cengiz, Bülent Ecevit University, Faculty of Dentistry, Department of Prosthodontics, 67600 Kozlu, Zonguldak, Turkey. Tel: +90 372 2613604, Fax: +90 372261 3603. e-mail: sedabc@hotmail.com 
Abstract: This study evaluated the influence of Er,Cr:YSGG laser surface conditioning on pushout bond strength of different root posts to the root dentin. Extracted ( $N=27, n=9$ per group) and endodontically treated human mandibular premolars were prepared to receive the posts. Three types of posts, namely quartz fiber (D), glass fiber (S) and zirconium dioxide post (C) were luted with resin cement. The posts were randomly assigned to one of the surface conditioning method: a) No conditioning, control (L0), b) Er,Cr:YSGG laser at $175 \mathrm{~mJ}, 3.5 \mathrm{~W}$ for $60 \mathrm{~s}$, with 60 $\mu \mathrm{s}$ pulse duration and repetition rate of $20 \mathrm{~Hz}(\mathrm{~L} 1)$ and c) at $225 \mathrm{~mJ}, 4.5 \mathrm{~W}$ for $60 \mathrm{~s}$, with $60 \mu \mathrm{s}$ pulse duration and repetition rate was $20 \mathrm{~Hz}$ (L2) irradiation. Six sections (two coronal, two middle, and two apical) were made in each tooth yielding to $1 \mathrm{~mm}$ thick specimens. The specimens were stored in distilled water at $37^{\circ} \mathrm{C}$ for $24 \mathrm{~h}$ and push-out bond strength (MPa) was tested in a Universal Testing Machine $(1 \mathrm{~mm} / \mathrm{min})$. Data were analysed using KruskallWallis and Dunns's post hoc tests $(\alpha=0.05)$. In group $D$, both laser treated groups (L1:16.16 $\pm 19.89 ; L 2: 8.24 \pm 9.26)$ presented significantly less bond strength compared to control group (L0:28.3 \pm 16.8$)(p<0.001)$. Mean push-out bond strength values did not significantly differ according to the root segments (coronal, middle, and apical) $(p=0.106)$. Application of Er,Cr:YSGG laser, with the parameters tested, did not increase the bond strength of zirconium glass fiber and zirconium oxide posts. Laser surface conditioning decreased the bond strength of quartz fiber posts in the root canal.

Keywords: Adhesion, bond strength, Er,Cr:YSGG laser, fiber post, zirconia post 


\section{Introduction}

Endodontically treated tooth with insufficient coronal structure is often restored with crowns. In the presence of insufficient dentin, post-core restoration is required to provide retention and support to the crown [1]. As a result of unfavourable colour of metal posts, such as a grayish shine through under the translucent ceramic crowns, around and through the surrounding gingiva [2], tooth coloured root post systems have gained attention for aesthetic reasons [3].

Among different root post options, fiber reinforced composite resin (FRC) post systems demonstrate successful clinical performance [4]. FRC posts increase the transmission of light within the root [5] and having low modulus of elasticity [6] they reduce the risk of root fracture [7] and eliminate corrosion related problems [8]. Typically, FRC posts are made of carbon, quartz, or glass fibers, embedded in a matrix of epoxy or methacrylate resin $[9,10]$. On the other hand, zirconium dioxide $\left(\mathrm{ZrO}_{2}\right)$ posts are partially stabilized with 3-6\% yttrium oxide $\left(\mathrm{Y}_{2} \mathrm{O}_{3}\right)$ and exhibit a polymorphic structure with monoclinic, tetragonal, and cubic crystalline phases [11]. High flexural strength, high fracture toughness, chemical stability, biocompatibility and favourable optical properties are advantages of zirconia as a restorative material [10]. Zirconia posts demonstrate high fracture resistance due to their high flexural strengths that is comparable to that of cast gold posts and cores or titanium posts [12].

Clinically, cementation failure and root fracture are the main problems affecting the survival of post systems [3]. In order to overcome this problem, surface conditioning of the post [13] and roughening the dentinal surfaces of the root canal are suggested increasing the retention of the posts [14]. In addition, selection of an appropriate adhesive system is critical for the success of FRC post. In that respect, achieving a chemical and micromechanical adhesion of the luting agent to both the post and the root canal dentin is essential [6].

Given the potential of some lasers, such as the neodymium: yttrium aluminum garnet (Nd:YAG), erbium (Er):YAG lasers to alter the dentin morphology, they may influence the adhesion of the posts to the root canal dentin $[15,16]$. Recently, lasers have been shown to 
provide relatively safe and easy means of altering the surface of various dental materials [17]. Many of the technological advances have been directed at the use of lasers in clinical settings as an alternative to acid etching of dental materials or teeth for improving bond strength [18]. Laser application was stated as an alternative treatment to other surface conditioning methods for enhancing the bond strength of the dental materials to metal surfaces $[19,20]$. The use of several laser types such as Nd:YAG, Er:YAG [21], erbium, chromium: yttrium, scandium, gallium, garnet (Er,Cr:YSGG) [22] and carbon dioxide $\left(\mathrm{CO}_{2}\right)$ lasers have been studied also for dental applications [23]. Er:YAG and Er,Cr:YSGG lasers have essentially similar basic properties apart from slight differences in terms of laser wavelength in the range of available pulse durations and in energy [24]. The use of pulsed erbium lasers, such as Er:YAG and Er,Cr:YSGG lasers has been considered for surface conditioning where the latter with $2.78 \mu \mathrm{m}$ wavelength has been used for conditioning porcelain brackets, indirect resin composites, leucite- or alumina-based ceramics [25]. High-intensity lasers have been recently investigated in order to increase the surface roughness of ceramic restorations, favouring adhesion of resinbased luting cements to ceramic surfaces through micromechanical interlocking [26]. The laser surface conditioning also alters the wettability characteristics of ceramics for improved adhesion and bonding [27]. Although Er,Cr:YSGG laser surface conditioning at $3 \mathrm{~W}$ output was found to increase adhesion of resin cements to zirconia [28], its effect on adhesion of glass and quartz fiber posts and eventually their bond strength to dentin surfaces is still unknown.

The objectives of this study therefore were to evaluate the effect of Er,Cr:YSGG laser surface conditioning operating at different parameters on the retention of FRC and zirconia posts in the root canal at different regions of the root compared to no conditioning. The null hypothesis tested were that a) Er,Cr:YSGG laser conditioning would not increase push-out bond strength of FRC and zirconia posts to dentin surfaces and b) the results would not be significantly different at coronal, middle and apical parts of the root. 


\section{Materials and Methods}

The brands, manufacturers, chemical composition and batch numbers of the materials used in this study are listed in Table 1.

Tooth selection

Extracted human mandibular premolar teeth ( $N=27, n=9$ per group) were obtained. All teeth were single rooted with a single canal, which was confirmed with multiple angulated radiographs. The soft-tissue remnants and calculi on the external root surface were removed mechanically using hand instruments. The crowns were removed at the cement-enamel junction with a diamond disc (Komet, Lemgo, Germany) under water-coolant at low speed to obtain a standardized root length of $15 \mathrm{~mm}$.

Root canal treatment

The working length of each root canal was established $1 \mathrm{~mm}$ short of the apical foramen. The root canal instrumentations were performed by single operator using ProTaper rotary instruments (Dentsply, Maillefer, Ballaigues, Switzerland) to the size of F3. The teeth were irrigated with $2 \mathrm{ml}$ of $2.5 \%$ sodium hypochloride after each instrument. Final irrigation was performed using $5 \mathrm{ml} 17 \%$ EDTA, $5 \mathrm{ml} 2.5 \% \mathrm{NaOCl}$ and $5 \mathrm{ml}$ distilled water, respectively. After drying, all root canals were obturated with matched tapered single-cone gutta-percha and AH 26 (Dentsply De Trey, Konstanz, Germany) sealer.

Post types and surface conditioning methods

Three types of post systems were used in this study, namely a) quartz fiber (D: D.T. Light post (\#2), Bisco Inc, Schaumburg, Illinois USA), glass fiber (S: SnowPost (\#16), Abrasive Technology, OH, USA) and zirconium dioxide post (C: CosmoPost ( $\mathrm{r}: 1.7 \mathrm{~mm})$, Ivoclar Vivadent AG, Schaan Liechtenstein).

The posts were randomly assigned to one of the following laser surface conditioning method:

Group LO: No conditioning was performed in this group and acted as the control group. 
Group L1: The post surfaces were conditioned using Er,Cr:YSGG laser (Waterlase; Biolase Technologies, San Clemente, CA, USA) at $175 \mathrm{~mJ}, 3.5 \mathrm{~W}$ for $60 \mathrm{~s}$, with $60 \mu \mathrm{s}$ pulse duration and repetition rate of $20 \mathrm{~Hz}$. The surfaces were irradiated from $1 \mathrm{~mm}$ distance on a fixed apparatus with $75 \%$ water and $85 \%$ air-cooling.

Group L2: In this group, were conditioned using Er,Cr:YSGG laser (Waterlase) at 225 mJ, $4.5 \mathrm{~W}$ for $60 \mathrm{~s}$, with $60 \mu \mathrm{s}$ pulse duration and repetition rate was $20 \mathrm{~Hz}$. The surfaces were irradiated from $1 \mathrm{~mm}$ distance on a fixed apparatus as described in Group L1.

After storage in saline solution for 7 days, gutta-percha was removed with drills to a length of $10 \mathrm{~mm}$. The root filling was removed with the same drill as deep as necessary for each post to be inserted until the two-thirds of the root length. The post space for each post was prepared with the matching drill of the post system. The same size posts were luted with dual polymerized resin cement (Panavia F 2.0, Kuraray Noritake Dental Inc., Osaka, Japan), according to the manufacturer's instructions. Excess cement was then removed with a scaler.

\section{Push-out test}

Each root was sectioned perpendicular to its long axis to obtain $1 \mathrm{~mm}$ thick specimens with a slow-speed diamond saw (Buehler Ltd., Lake Bluff, IL, USA) under water coolant. Altogether, 198 sections were obtained from each tooth of which 77 were from the coronal, 64 from middle and 57 from apical regions of the roots. The specimens were stored in distilled water at $37^{\circ} \mathrm{C}$ for $24 \mathrm{~h}$ in an incubator until tests.

Push-out test was performed using a cylindrical plunger mounted on the Universal Testing Machine (Instron, Canton, MA, USA). Compressive load was applied at a crosshead speed of 1 $\mathrm{mm} / \mathrm{min}$ until the post segment was dislodged from the root to the apical aspect in the apicalcoronal direction. The plunger tip size was selected and positioned to contact only the post, without stressing the surrounding root canal walls.

The initial bond strength result ( $\mathrm{MPa}$ ) was calculated dividing the maximum load ( $\mathrm{N})$ by the area of adhesion surface $\left(\mathrm{mm}^{2}\right)$. The adhesion area of each section was computed as the area 
of the lateral surface of a cone, using the formula:

$S I=\pi(r+R) a$

where $\pi=3.14, \mathrm{R}$ is the coronal radius, $\mathrm{r}$ is the apical radius, $\mathrm{a}$ is the apothem, computed using the formula:

$a=\left[h^{2}+(R-r)^{2}\right]^{1 / 2}$

where $\mathrm{h}$ is the thickness of the slice.

One post from each group was randomly selected for scanning electron microscopy (SEM) (Quanta 400F, FEI, Oregon, USA) evaluation. The SEM photomicrographs were obtained at x150 and x1000 magnification.

Statistical analysis

Statistical analyses were performed with SPSS 19.0 software (SPSS Inc., Chicago, IL, USA). Distribution of data was assesed using Shapiro-Wilk test. The means of each group were analyzed by Kruskall-Wallis and Dunns's post hoc tests with push out bond strength (MPa) as the dependent variable and post type (3 levels: quartz fiber, glass fiber, zirconia), surface conditioning with laser (2 levels: L1 versus L2) and root level (3 levels: coronal, middle, apical) as the independent factors. $P$ values less than 0.05 were considered to be statistically significant in all tests.

\section{Results}

Push-out bond strength results (MPa) were significantly affected by the post type $(p<0.001)$, laser surface conditioning $(p<0.001)$, but not the root level $(p>0.001)$.

While with the post type D, control group (LO) showed significantly higher results compared to both laser conditioning ( L1 and L2) $(p<0.001)$ (Table 2), with the post type $S$, no significant difference was found between the laser-conditioned ( $\mathrm{L} 1$ and $\mathrm{L} 2$ ) and control groups (L0) $(p=0.057)$. In Group C, L1 and L2 increased the bond strength yet being not significantly different compared to the control, $L 0(p=0.158)$. 
The push-out bond strength values did not vary significantly according to the root segments including coronal, middle, and apical (Table 3).

SEM images presented some irregularities on $C$ type of posts but large defects and cracks were evident in post types D and S, respectively after the laser conditioning methods (Figs.1-3a-f.)

\section{Discussion}

This study evaluate the effect of Er,Cr:YSGG laser surface conditioning at different operational parameters on the retention of FRC and zirconia posts in the root canal at different regions of the root compared to no conditioning. Based on the results of this study, since application of Er,Cr:YSGG laser did not increase the push-out bond strength and no regional difference was observed, the null hypothesis could be accepted.

Since the long-term success of endodontically treated tooth is dependent on the ability of the post to resist the chewing forces [5], retention of the post becomes an important factor for the success of the restoration [29]. Composition of the FRC post affects the bond strength of resinbased luting agent to the post [25]. Therefore, two different FRC and a zirconia post were selected. When the post compositions were considered, glass fiber and quartz fiber posts demonstrated higher bond strength than zirconia ceramic post $[3,31]$. The higher push-out bond strength of the FRC groups could be attributed to the superior adhesion between the methacrylate resin matrix of the fiber post and the methacrylate-based adhesives and resin cement also weaker bonding affinity of the resin cement to the ceramic posts $[32,33]$.

In this study, dual polymerized resin cement was used to lute the posts in the root canal. Photopolymerization from the top of the post coronally, is not sufficient to polymerize the photopolymerized adhesives and resin cements optimally. For this reason. dual-polymerized or chemically-polymerized resin cements were recommended for the cementation of fibre posts [34]. Adhesive resin cements, such as Panavia F2.0 used in this study, contains 10- 
Methacryloyloxydecyl dihydrogen phosphate (10-MDP) functional monomer. This monomer can establish favourable adhesion to both the dental tissues and the metal oxides or zirconia [35]. The results in this study did not differ significantly in the coronal, middle and apical regions of the root. Consequently, it can be stated that the resin cement used, presented similar levels of polymerization even in the most apical parts of the roots, regardless of the post type.

Adhesion of resin-based materials to dental materials after laser application is highly affected by ablation parameters such as the duration, frequency and power of irradiation [36]. The output power of Er,Cr:YSGG laser can vary from 0 to $6 \mathrm{~W}$ [37]. Various output values were evaluated for dental use ranging from 0.5 to $1 \mathrm{~W}, 3$ to $4.5 \mathrm{~W}$ and $6 \mathrm{~W}[38,39]$. In the present study, high output values were tested since the laser was applied to the post surfaces that were not in contact with dental tissues. In a similar study, Er:YAG laser was tested on quartz fiber post and no significant effect was observed on the push-out bond strength compared to the control group [6]. Likewise, in the present study, no significant difference was found in S group that consisted of zircon-glass fiber. Interestingly, in laser treated D group, the push-out bond strength values were even less than those in the control groups. The surface analysis in this group presented large defects possibly affecting the wettability of the resin cement on the methacrylate matrix of the FRC post. In this study, no chemical analysis was made but whether laser conditioning decomposes the methacrylate groups and free radicals on the post surface or not needs further investigation.

Miranda et al. [36] evaluated the surface roughness on $\mathrm{ZrO}_{2}$ surfaces after $\mathrm{Er}, \mathrm{Cr}$ :YSGG laser irradiation at $1.5 \mathrm{~W} / 20 \mathrm{~Hz}$ with air-water cooling proportion of $80 / 25 \%$ and reported that laser irradiation decreased the surface roughness. Previous studies in this regard showed controversial results $[20,37,40]$. One reason for this could be the different methods employed for roughness measurements. In the present study, 3.5 and 4.5W laser application did not increase the bond strength significantly. SEM analysis revealed that Er,Cr:YSGG laser application resulted in irregularities on the surface of zirconia post. In addition, untreated specimens showed 
more flat surfaces than laser treated specimens. Due to the round nature of the posts, surface roughness is difficult to measure in a predictable way. Future studies should correlate roughness with the bond strength results.

Kurt et al. [41] investigated the effects of Er:YAG laser at different power settings on the pushout bond strength of resin composite core materials on glass fiber posts. Unfortunately, Er:YAG laser application significantly decreased the bond strength of cores to fiber posts compared to the untreated group. The reason for such results was attributed to the damage on the surface as a result of heat. Similarly, in the present study with comparable number of specimens, the lowest mean push-out bond strength values for quartz fiber post was recorded with the highest power setting of Er,Cr:YSGG. On the other hand, when evaluating the effect of Er,Cr:YSGG laser on bond strength between zirconia ceramic and resin cement, 3W output power has been reported to be sufficient for roughening the zirconia surface and establish improved bond strength of resin cement [28]. SEM findings indicated a smother surface on the zirconia posts but higher bond strength results, still being not significant compared to the control group. This could be explained with more reliable chemical polymerization of 10-MDP functional monomer of the resin cement on zirconia [42].

The laser application on the post surface has gained attention as a current approach. Er,Cr:YSGG with two different power settings was used in this study. The type of laser, energy parameters and ablation rates may yield to different results in the treatment of post surfaces. Limited output values, the use of single laser type, and selected posts could be expanded in further studies considering other laser types and energy parameters on larger sample size. 


\section{Conclusions}

From this study, the following could be concluded:

1. The application of Er,Cr:YSGG laser with the studied parameters did not increase the pushout bond strength of glass, quartz fiber or zirconia root posts. Laser application even decreased the results in quartz fiber post group.

2. The push-out bond strength values did not vary significantly considering the root segments (coronal, middle, and apical).

3. Er,Cr:YSGG laser application changed the surface morphology of the root posts studied, presenting larger defects and cracks on quartz and fiber compared to zirconia posts.

\section{Clinical Relevance}

Glass, quartz fiber or zirconia root posts conditioned with Er,Cr:YSGG laser did not benefit from increased push-out bond strength in the root canal.

\section{Acknowledgement}

This study was supported by the research funds of Bülent Ecevit University (No. 2012-21-0007).

\section{Conflict of interest}

The authors did not have any commercial interest in any of the materials used in this study. 


\section{References}

[1] Carter JM, Sorensen SE, Johnson RR, Tietelbaum RL, Levine MS. Punch shear tested of extracted vital and endodontically treated teeth. J. Biomech 1983;16:841-848.

[2] Bitter K, Priehn K, Martus P, Kielbassa AM. In vitro evaluation of push-out bond strengths of various luting agents to tooth-colored posts. J. Prosthet Dent 2006;95:302-310.

[3] Akgungor G, Sen D, Aydın M. Influence of different surface treatments on the short-term bond strength and durability between a zirconia post and a composite resin core material. $\mathrm{J}$ Prosthet Dent 2006;99: 388-399.

[4] Malferrari S, Monaco C, Scotti R. Clinical evaluation of teeth restored with quartz fiberreinforced epoxy resin posts. Int J Prosthodont 2003;16:39-44.

[5] Balbosh A, Kern M. Effect of surface treatment on retentionof glass-fiber endodontic posts. J Prosthet Dent 2006;95:218-223.

[6] Tuncdemir AR, Yıldırım C, Güller F, Özcan E, Usumez A. The effect of post surface $t$ reatments on the bond strength of fiber posts to root surfaces. Lasers Med Sci 2013;28:13-18.

[7] Schwartz RS, Robbins JW. Post placement and restoration of endodontically treated teeth: a literature review. J Endod 2014;30:289-301.

[8] Kedici SP, Aksut AA, Kilicarslan MA, Bayramoglu G, Gokdemir K. Corrosion behaviour of dental metals and alloys in different media. J Oral Rehabil 1998;25:800-808.

[9] Baba NZ, Golden G, Goodacre CJ. Nonmetallic prefabricated dowels:a review of compositions, properties, laboratory, and clinical test results. J.Prosthodont 2009;18:527-536.

[10] Goracci C, Ferrari M. Current perspectives on post systems: a literature review. Aust Dent J 2011;5:77-83.

[11] Xible AA, de Jesus Tavarez RR, de Araujo dos R, Bonachela WC. Effect of silica coating and silanization on flexural and composite-resin bond strengths of zirconia posts: An in vitro study. J Prosthet Dent 2006;95:224-229. 
[12] Heydecke G, Butz F, Strub JR. Fracture strength and survival rate of endodontically treated maxillary incisors with approximal cavities after restoration with different post and core systems: an in-vitro study. J Dent 2001;29:427-433.

[13] Sahafi A, Peutzfeldt A, Asmussen E, Gotfredsen K. Bond strength of resin cement to dentin and to surface-treated posts of titanium alloy, glass fiber, and zirconia. J Adhes Dent 2003;5:153-162.

[14] Nergiz I, Schmage P, Platzer U, McMullan-Vogel CG. Effect of different surface textures on retentive strength of tapered posts. J Prosthet Dent 1997;8:451-457.

[15] Yamada MK, Uo M, Ohkawa S, Akasaka T, Watari F. Three-dimensional topographic scanning electron microscope and Raman spectroscopic analyses of the irradiation effect on teeth by Nd:YAG, Er: YAG, and CO2 lasers. J Biomed Mater Res B Appl Biomater 2004;71:715.

[16] Ghiggi PC, DallAgnol RJ, Burnett LH Jr, Borges GA, Spohr AM. Effect of the Nd:YAG and the Er:YAG laser on the adhesive-dentin interface: a scanning electron microscopy study. Photomed Laser Surg 2010;28:195-200.

[17] Akin H, Tugut F, Akin GE, Guney U, Mutaf B. Effect of Er: YAG laser application on the shear bond strength and microleakage between resin cements and Y-TZP ceramics. Lasers Med Sci 2012;27:333-338.

[18] Mannocci F, Sheriff M, Watson TF, Vallittu PK. Penetration of bonding resins into fibrereinforced composite posts: a confocal microscopic study. Int Endod J 2005;38:46-51.

[19] Yilmaz A, Akyil MS, Hologlu B. The effect of metal primer application and Nd: YAG laser irradiation on the shear-bond strength between polymethyl methacrylate and cobalt-chromium alloy. Photomed Laser Surg 2011;29:39-45.

[20] Cavalcanti AN, Pilecki P, Foxton RM, Watson TF, Oliveira MT, Gianinni M, Marchi GM. Evaluation of the surface roughness and morphologic features of Y-TZP ceramics after different surface treatments. Photomed Laser Surg 2009;27:473-479. 
[21] da Silva Ferreira S, Hanashiro FS, de Souza-Zaroni WC, Turbino ML, Youssef MN. Influence of aluminum oxide sandblasting associated with Nd: YAG or Er: YAG lasers on shear bond strength of a feldspathic ceramic to resin cements. Photomed Laser Surg 2010;28:471475.

[22] Kimyai S, Mohammadi N, Navimipour EJ, Rikhtegaran S. Comparison of the effect of three mechanical surface treatments on the repair bond strength of a laboratory composite. Photomed Laser Surg 2010;28:S25-30.

[23] Chen JR, Oka K, Kawano T, Goto T, Ichikawa T. Carbon dioxide laser application enhances the effect of silane primer on the shear bond strength between porcelain and composite resin. Dent Mater J 2010; 29:731-737.

[24] Perhavec T, Diaci J. Comparison of Er:YAG and Er, Cr:YSGG lasers used in dentistry. J Oral Laser Appl 2008;8:87-94.

[25] Eduardo CP, Bello-Silva MS, Moretto SG, Cesar PF, Freitas PM. Microtensile bond strength of composite resin to glass-infiltrated alumina composite conditioned with $\mathrm{Er}, \mathrm{Cr}$ :YSGG laser. Lasers Med Sci. 2012;27:7-14.

[26] da Silveira BL, Paglia A, Burnett LH, Shinkai RS, de Paula Eduardo C, Spohr AM. Microtensile bond strength between a resin cement and an aluminous ceramic treated with Nd:YAG laser, Rocatec System, or aluminum oxide sandblasting. Photomed Laser Surg 2005;23:543548.

[27] Usumez A, Inan, O, Aykent, F. Bond strength of a silicone lining material to aluminaabraded and lased denture resin. J Biomed Mater Res 2004;71:196-200.

[28] Zanjani VA, Ahmadi H, Nateghifard A, Ghasemi A, Torabzadeh H, Tabrizi MA, Alikhani F, Razi R, Nateghifard A. Effect of different laser surface treatment on microshear bond strength between zirconia ceramic and resin cement. J Invest Clin Dent 2015;6:294-300.

[29] Usumez A, Aykent F. Bond strengths of porcelain laminate veneers to tooth surfaces prepared with acid and Er, Cr: YSGG laser etching. J Prosthet Dent 2003;90:24-30. 
[30] Choi Y, Pae A, Park EJ, Wright RF. The effect of surface treatment of fiber-reinforced posts on adhesion of a resin-based luting agent. J Prosthet Dent 2010;103:362-368.

[31] Perdigao J, Geraldeli S, Lee IK. Push-out bond strengths of tooth colored posts bonded with different adhesive systems. Am J Dent 2004;17:422-426.

[32] Ferrari M, Vichi A, Grandini S. Efficacy of different adhesive techniques on bonding to root canal walls: An SEM investigation. Dent Mater 2001;17:422-429.

[33] Vano M, Cury AH, Goracci C, Chieffi N, Gabriele M, Tay RF, Ferrari M. Retention of fiber posts cemented at different time intervals in canals obturated using an epoxy resin sealer. $\mathrm{J}$ Dent 2008;36:801-807.

[34] Giachetti L, Russo DS, Baldini M, Bertini F, Steier LM, Ferrari M. Push-out strength of translucent fibre posts cemented using a dual-curing technique or a light-curing self-adhering material. Int Endod J 2012;45:249-256.

[35] Casucci A, Monticelli F, Goracci C. Effect of surface pre-treatments on the zirconia ceramicresin cement microtensile bond strength. Dent Mater 2011;27:1024-1030.

[36] Miranda PV, Rodrigues JA, Blay A, Shibli JA, Cassoni A. Surface alterations of zirconia and titanium substrates after Er, Cr:YSGG irradiation. Lasers Med Sci 2015;30:49-50.

[37] Gökçe B. Effects of Er: YAG laser irradiation on dental hard tissues and all-ceramic materials: SEM Evaluation. In: Viacheslav Kazmiruk, editor. Scanning. Electron. Microscopy. 2012.New York; In tech; p 179-212.

[38] Oskoee PA, Kachoei M, Rikhtegaran S, Fathalizadeh F, Navimipour EJ. Effect of surface treatment with sandblasting and Er,Cr:YSGG laser on bonding of stainless steel orthodontic brackets to silver amalgam. Med Oral Pathol Oral Cir Bucal 2012;1:17:e292-296.

[39] Obeidi A1, Liu PR, Ramp LC, Beck P, Gutknecht N. Acid-etch interval and shear bond strength of Er,Cr:YSGG laser-prepared enamel and dentin. Lasers Med Sci 2010;25:363-369.

[40] Demir N, Subasi MG, Ozturk AN. Surface roughness and morphologic changes of zirconia following different surface treatments. Photomed Laser Surg 2012;30:339-345. 
[41] Kurt M, Guler AU, Duran I, Uludamar A, Inan O. Effects of different surface treatments on the bond strength of glass fiber-reinforced composite root canal posts to composite core material. J Dent Sci 2012;7: 20-25.

[42] May LG, Passos SP, Capelli DB, Özcan M, Bottino MA, Valandro LF.Effect of silica coating combined to a MDP-based primer on the resin bond to Y-TZP ceramic. J Biomed Mater Res B Appl Biomater 2010;95:69-74. 


\section{Captions to tables and figures:}

\section{Tables:}

Table 1. Brands, types, chemical compositions and manufacturers of the root posts and the luting cement used in this study.

Table 2. Mean push-out bond strengths (MPa), standard deviations of the experimental groups and significant differences. The same supercript letters for post sytem in each row, indicates no significant difference.

Table 3. Mean push-out bond strength (MPa) and standard deviations of root posts depending on the root sections. c: coronal; m: middle; a: apical. The same supercript letters for post sytem in each row, indicates no significant difference. See Table 1 for group abbreviations.

\section{Figures:}

Figs. 1a-f. SEM photomicrographs of D post surface after L0, L1 and L2 conditioning at x150 and $\times 1000$. Note that Er,Cr:YSGG laser conditioning caused ablation of the epoxy/methacrylate resin creating large defects and exposure of the quartz fibers as well as cracking of some fibers in $1 \mathrm{~b}$ (L1 group) and 1c (L2 group) indicated by the arrow.

Figs. 2a-f. SEM photomicrographs of S post surface after L0, L1 and L2 conditioning at x150 and $\times 1000$. Note that Er,Cr:YSGG laser conditioning caused ablation of the epoxy/methacrylate resin creating large defects and exposure of the glass fibers as well as cracking of some fibers in $\mathbf{2 b}$ (L1 group) and 2c (L2 group) indicated by the arrow.

Figs. 3a-f. SEM photomicrographs of C post surface after L0, L1 and L2 conditioning at x150 and $\times 1000$. Note that Er,Cr:YSGG laser conditioning caused limited surface irregularities in $3 \mathbf{e}$ (L1 group) and 3f (L2 group) indicated by the arrow. 
Tables:

\begin{tabular}{|c|c|c|c|}
\hline Brand & Type & Chemical composition & Manufacturer \\
\hline Snowpost (S) & Fiber post & $\begin{array}{l}\text { Silica, zircon-glass fiber, } \\
\text { epoxy resin matrix }\end{array}$ & $\begin{array}{l}\text { GC Europe, Tokyo, } \\
\text { Japan }\end{array}$ \\
\hline DT Light (D) & Quartz post & rtz fiber, epoxy resin matrix & $\begin{array}{l}\text { Ultradent, South } \\
\text { Jordan, Utah, USA }\end{array}$ \\
\hline Cosmopost (C) & Zirconia post & $\mathrm{ZrO}_{2}, \mathrm{HfO}_{2}, \mathrm{Y}_{2} \mathrm{O}_{3}, \mathrm{Al}_{2} \mathrm{O}_{3}$ & $\begin{array}{l}\text { Ivoclar, Vivadent, } \\
\text { Schaan, } \\
\text { Liechtenstein }\end{array}$ \\
\hline Panavia F 2.0 & $\begin{array}{l}\text { Luting resin } \\
\text { composite }\end{array}$ & $\begin{array}{l}\text { Base: bis-GMA, UDMA, } \\
\text { TEGDMA, fillers, ytterbium } \\
\text { trifluoride, stabilizers, } \\
\text { pigments, benzoyl peroxide }\end{array}$ & $\begin{array}{l}\text { Kuraray, Noritake } \\
\text { Dental Inc., Osaka, } \\
\text { Japan }\end{array}$ \\
\hline
\end{tabular}

Table 1. Brands, types, chemical compositions and manufacturers of the root posts and the luting cement used in this study. 


\begin{tabular}{|c|c|c|c|c|c|c|c|c|c|}
\hline & \multicolumn{3}{|c|}{ D } & \multicolumn{3}{|c|}{ C } & \multicolumn{3}{|c|}{$\mathbf{S}$} \\
\hline & $\begin{array}{c}\mathrm{L0} \\
(\mathrm{n}=25)\end{array}$ & $\begin{array}{c}\mathrm{L1} \\
(\mathrm{n}=23)\end{array}$ & $\begin{array}{c}\mathrm{L} 2 \\
(\mathrm{n}=23)\end{array}$ & $\begin{array}{c}\text { L0 } \\
(n=20)\end{array}$ & $\begin{array}{c}\mathrm{L1} \\
(\mathrm{n}=21)\end{array}$ & $\begin{array}{c}\text { L2 } \\
(n=23)\end{array}$ & $\begin{array}{c}\text { L0 } \\
(\mathrm{n}=21)\end{array}$ & $\begin{array}{c}\text { L1 } \\
(n=19)\end{array}$ & $\begin{array}{c}\text { L2 } \\
(n=26)\end{array}$ \\
\hline $\begin{array}{l}\text { Mean push-out } \\
\text { bond strength } \\
\text { (MPa) } \pm \text { SD }\end{array}$ & $28.3 \pm 16.8^{\mathrm{a}}$ & $16.16 \pm 19.89^{b}$ & $8.24 \pm 9.26^{b}$ & $8.22 \pm 11.12^{c}$ & $12.52 \pm 18.34^{c}$ & $30.31 \pm 33.07^{C}$ & $43.89 \pm 35.76^{d}$ & $20.34 \pm 9.9^{d}$ & $26.14 \pm 18.45^{d}$ \\
\hline p & \multicolumn{3}{|c|}{$<0.001$} & \multicolumn{3}{|c|}{$=0.158$} & \multicolumn{3}{|c|}{$=0.057$} \\
\hline
\end{tabular}

Table 2. Mean push-out bond strengths (MPa), standard deviations of the experimental groups and significant differences. The same supercript letters

for post sytem in each row, indicates no significant difference. 


\begin{tabular}{|c|c|c|c|c|c|c|c|c|c|}
\hline & \multicolumn{3}{|c|}{ D } & \multicolumn{3}{|c|}{ C } & \multicolumn{3}{|c|}{$\mathbf{S}$} \\
\hline & $\begin{array}{c}\mathbf{c} \\
(n=27)\end{array}$ & $\underset{(n=24)}{\mathbf{m}}$ & $\begin{array}{c}a \\
(n=20)\end{array}$ & $\begin{array}{c}\mathbf{C} \\
(n=25)\end{array}$ & $\begin{array}{c}\mathbf{m} \\
(n=20)\end{array}$ & $\begin{array}{c}\mathbf{a} \\
(n=19)\end{array}$ & $\begin{array}{c}\text { C } \\
(n=25)\end{array}$ & $\begin{array}{c}\mathbf{m} \\
(n=20)\end{array}$ & $\begin{array}{c}a \\
(n=18)\end{array}$ \\
\hline $\begin{array}{c}\text { Mean push-out } \\
\text { bond strength } \\
(\mathrm{MPa}) \pm \mathrm{SD}\end{array}$ & $17.46 \pm 16.14^{a}$ & $16.4 \pm 15.22^{\mathrm{a}}$ & $0.19 \pm 22.98^{a}$ & $22.49 \pm 28.4^{b}$ & b. $36 \pm 20.44^{b}$ & $8,48 \pm 23,64^{b}$ & $34.31 \pm 29.15^{c}$ & $23.27 \pm 21.36^{c}$ & $32.58 \pm 24.81^{\circ}$ \\
\hline p & \multicolumn{3}{|c|}{$=0.977$} & \multicolumn{3}{|c|}{$=0.111$} & \multicolumn{3}{|c|}{$=0.114$} \\
\hline
\end{tabular}

Table 3. Mean push-out bond strength (MPa) and standard deviations of root posts depending on the root sections. c: coronal; m: middle; a: apical. The same supercript letters for post sytem in each row, indicates no significant difference. See Table 1 for group abbreviations. 
Figures:
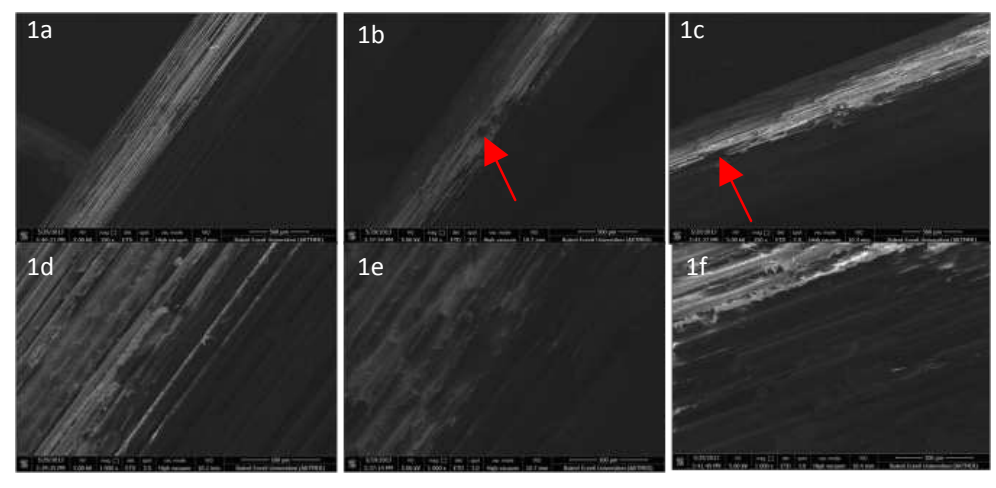

Figs. 1a-f. SEM photomicrographs of D post surface after LO, L1 and L2 conditioning at $x 150$ and $x 1000$. Note that Er,Cr:YSGG laser conditioning caused ablation of the epoxy/methacrylate resin creating large defects and exposure of the quartz fibers as well as cracking of some fibers in $1 \mathrm{~b}(\mathrm{~L} 1$ group) and 1c (L2 group) indicated by the arrow.
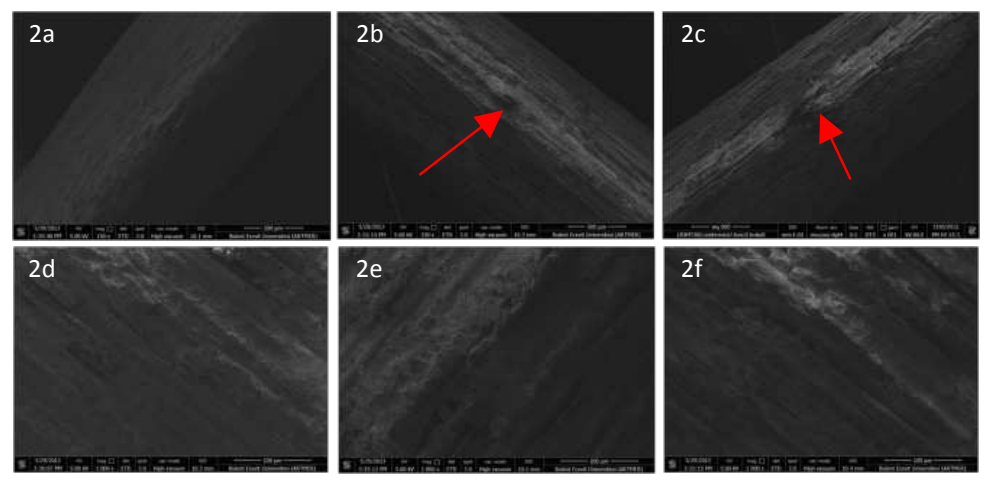

Figs. 2a-f. SEM photomicrographs of S post surface after LO, L1 and L2 conditioning at x150 and $\mathrm{x} 1000$. Note that Er,Cr:YSGG laser conditioning caused ablation of the epoxy/methacrylate resin creating large defects and exposure of the glass fibers as well as cracking of some fibers in $2 b$ (L1 group) and 2c (L2 group) indicated by the arrow. 


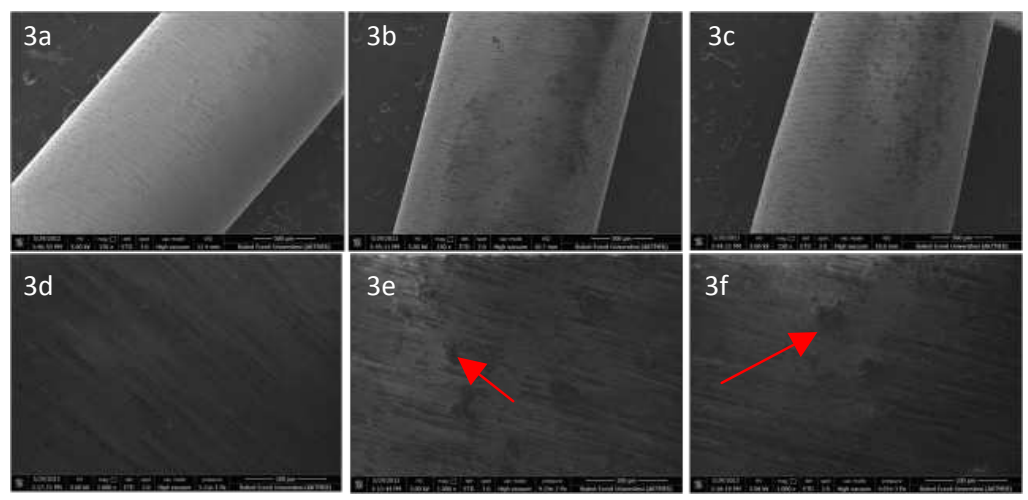

Figs. 3a-f. SEM photomicrographs of C post surface after LO, L1 and L2 conditioning at $x 150$ and $\mathrm{x} 1000$. Note that Er,Cr:YSGG laser conditioning caused limited surface irregularities in $3 e$ (L1 group) and $3 f$ (L2 group) indicated by the arrow. 